\title{
Article 19. Model Contractual Clauses
}

1. Each Party shall encourage, as appropriate, the development, update and use of sectoral and cross-sectoral model contractual clauses for mutually agreed terms.

2. The Conference of the Parties serving as the meeting of the Parties to this Protocol shall periodically take stock of the use of sectoral and cross-sectoral model contractual clauses.

\section{Overview}

Article 19 identifies Parties' responsibility to encourage the development and use of model clauses for MAT, namely the private ABS contract to be negotiated between an individual provider and an individual user. ${ }^{1}$ As discussed above, the Protocol contains little guidance on the content of $\mathrm{MAT}^{2}$ although this is the only tool that explicitly aims to operationalize the Protocol's objective to achieve fairness and equity in sharing benefits ${ }^{3}$ and is expected to be enforceable across jurisdictions. ${ }^{4}$ Article 19, therefore, opens the door to the future development of further international guidance on the content of MAT by tapping into user-led practices and other ABs stakeholders' experience in developing and operationalizing standard contractual clauses. ${ }^{5}$

The rationale of Article 19 is the need to create legally enforceable and inter-operable ABs contracts in different jurisdictions that may have different national ABs frameworks and whose national courts may have different standards in recognizing as valid and enforcing contracts. ${ }^{6}$ This was in fact one of the main concerns related to legal certainty ${ }^{7}$ that arose from the early implementation of ABs laws and motivated the negotiations of the Nagoya Protocol.

1 Generally on MAT, see this commentary on Article 5, section 5.

2 Nagoya Protocol Article 6.3(g) and this commentary on Article 6, section 7.

3 See this commentary on Article 1 and Conclusions to this commentary, section 2.

4 See this commentary on Article 18.

5 Chiarolla, Louafi and Schloen, “Analysis of the Relationship," op. cit., 118.

6 Young, "An International Cooperation Perspective," op. cit., 490-494; and Tomme Young, "Applying Contract Law to ABS," in Contracting for ABs: The Legal and Scientific Implications of Bioprospecting Contracts, ed. Shakeel Bhatti et al., (Gland: IUCN, 2009), 39.

7 Nagoya Protocol 9th preambular recital.

(C) Elisa Morgera, Elsa Tsioumani, and Matthias Buck, 2015.

This is an open access chapter distributed under the terms of the Creative Commons Attribution-Noncommercial 3.0 Unported (CC-BY-NC 3.0) License. 
The importance of standardized contractual clauses ${ }^{8}$ therefore lies in their potential contribution to the predictability and consistency of ABS transactions, thereby reducing burdens and transaction costs in establishing $\mathrm{MAT}^{9}$ and monitoring compliance..$^{10}$ It should be stressed, however, that model contractual clauses cannot replace the need for Parties to develop their national ABS frameworks supporting and regulating the negotiations of MAT. ${ }^{11}$

Notably, Article 19 emphasizes the importance of developing model contractual clauses for specific sectors of ABS transactions, as well as cross-sectoral ones. This reflects the understanding that each sector is part of a unique research network or market, with distinct practices of accessing and using genetic resources and undertaking research and development. ${ }^{12}$ Article 19 may thus possibly serve to further understand how the Protocol operates in different sectors. In addition, implementation of Article 19 may arguably also contribute to promoting best practices and building the capacity of concerned sectors in countries in which such sectors are less developed. ${ }^{13}$

The following sections will analyze the obligation of Parties, and the mandate for the Protocol's governing body contained in Article 19, in turn.

\section{$2 \quad$ Obligation for Parties}

Article 19(1) creates a best-endeavor obligation for all Parties to support the development, update and use of model contractual clauses for MAT. This

8 See "Database of Model Contractual Clauses," СвD, accessed 30 November 2013, <www. cbd.int/abs/resources/contracts.shtml>; and wIPo online searchable database of biodiversity-related ABS agreements, with a particular emphasis on the intellectual property aspects of such agreements: "Biodiversity-Related Access and Benefit-Sharing Agreements," WIPO, accessed 30 November 2013, <www.wipo.int/tk/en/databases/contracts/index.html>.

$9 \quad$ See Nagoya Protocol Article 6(3)(g) and this commentary on Article 6, section 7.

10 See this commentary on Article 18.

11 We are grateful to Tomme Young for having drawn our attention to this point. The Protocol negotiators reflected this understanding when they placed draft operational text on model clauses in a section on tools to support compliance, rather than in a section on tools for enforcing compliance. See EN B 9/465, "Summary of the Seventh Meeting of the Working Group on ABs," 6-7; and ENB, "Summary of the Eighth Meeting of the Working Group on Access and Benefit-Sharing of the Convention on Biological Diversity: 9-15 November 2009," Vol. 9 No. 489, 18 November 2009, 7-9.

12 Св Secretariat, "Access and Benefit-sharing in Practice," op. cit., 8.

13 Ibid. Note that the Protocol provision on capacity building explicitly points also to the needs of ABS 'stakeholders': Nagoya Protocol Article 22(5)(i) and this commentary on Article 22, section 4 . 
obligation can be undertaken unilaterally by Parties establishing 'default' or 'standard' MAT for specific categories of genetic resources under their jurisdiction or for specific cases. ${ }^{14}$ Such default MAT would likely have to be accepted by a user upon applying for access to genetic resources and/or traditional knowledge, or could apply automatically unless different MAT are negotiated..$^{15}$ Parties could also implement this obligation collectively in the context of bilateral or regional ABs frameworks, ${ }^{16}$ and at the multilateral level. One precedent of multilateral nature is the standard Material Transfer Agreement adopted by the ITPGRFA Governing Body for exchanges of material within its Multilateral System. ${ }^{17}$ In addition, States have initiated work on model clauses for other sectors of genetic resources for food and agriculture, which could include for instance animal genetic resources and microorganisms, under the FAO Commission on Genetic Resources for Food and Agriculture. ${ }^{18}$

It should be further noted that model contractual clauses are included among the information that can be voluntarily submitted by Parties to the ABS Clearinghouse. ${ }^{19}$ In addition, Article 19 should be read in conjunction with the obligation for Parties to endeavor to support, as appropriate, the development by indigenous and local communities of model contractual clauses for benefit-sharing arising from the utilization of traditional knowledge associated with genetic resources. ${ }^{20}$ Article 19 is further related to the obligation to encourage individual users and providers to include provisions in MAT on information-sharing and contractual reporting aimed at monitoring the

14 See this commentary on Article 6, section 3.2.

15 See for instance the standard conditions that apply to bioprospecting activities with non-commercial purpose on Commonwealth territories in Australia: "Permits for NonCommercial Purposes," Government of Australia, accessed 30 November 2013, <www. environment.gov.au/node/14465>.

16 See this commentary on Article 4, section 3.

17 In practice, the SMTA of the ITPGRFA is also used for transactions of plant genetic resources outside the Treaty's Multilateral System acquired before the Treaty's entry into force, in particular between the international agricultural research centres of the Consultative Group on International Agricultural Research. See this commentary on Article 4, fn. 99; and Chiarolla, Louafi and Schloen, "Analysis of the Relationship," op. cit., 108-109.

18 The CGRFA, "Report of the fourteenth regular session," paragraph 40 (viii), requested its Secretary to compile the information obtained by Parties for consideration by the Commission's intergovernmental technical working groups, to enable the Commission to take a decision on the collection of model contractual clauses for subsectors of genetic resources other than plant genetic resources for food and agriculture at its fifteenth Regular Session.

19 Nagoya Protocol Article 14(3)(b). See this commentary on Article 14, section 4.

$20 \quad$ Nagoya Protocol Article 12(3)(c). See this commentary on Article 12. 
utilization of genetic resources once they have left the jurisdiction of the country providing PIC. ${ }^{21}$

\section{$3 \quad$ Mandate for the Protocol's Governing Body}

Article 19(2) tasks the Protocol's governing body to periodically 'take stock' of the use of standardized contractual clauses. At a minimum, in accordance with СвD practice, the governing body will likely invite Parties on a periodic basis to submit reports of sectoral reviews and examples of model contractual clauses, synthesize this information and make it available through the ABS Clearinghouse. ${ }^{22}$ The wording of Article 19(2) does not exclude the possibility ${ }^{23}$ that the governing body could also endorse certain model contractual clauses, whether generally or as a 'predetermination of enforceability' that would enable Parties to ensure their automatic recognition in domestic courts. ${ }^{24}$ As endorsed by the Protocol's governing body, certain model contractual clauses could come to represent 'subsequent practice in the application of the treaty which establishes the agreement of the $[\mathrm{P}]$ arties regarding its interpretation.'25 It remains to be seen, however, whether such an assessment would be conducted by the Protocol's governing body, could require the establishment of an ad hoc process given the high number of standard contractual clauses to be examined, or even be a function that might be subsumed under the Protocol's compliance procedures and mechanisms. ${ }^{26}$

The Protocol, overall, seeks to tap into normative activities undertaken by various ABS stakeholders such as the research community, the private sector, indigenous peoples and local communities, and NGOs at the national (but also sub-national and transnational) levels as a bottom-up source of inspiration for multilateral discussions on ways to facilitate implementation of and compliance with the Protocol. ${ }^{27}$

21 Nagoya Protocol Article 17(1)(b). See this commentary on Article 17. The availability of relevant model contractual clauses could also support the effective implementation of Nagoya Protocol Articles 6(3)(g), 7 and 18(1).

22 Greiber et al., Explanatory Guide, op. cit., 194.

23 Although it does not mandate the Protocol's governing body to do so. Compare Nagoya Protocol Article 20(2). See also this commentary on Article 20.

24 Young, “An International Cooperation Perspective," op. cit., 493. Such endorsement could be provided on the basis of Nagoya Protocol Article 26(4)(f).

25 VCLT, Article 31(3)(b).

26 We are grateful to Geoff Burton for a useful exchange of ideas on this point.

27 Morgera, Buck and Tsioumani, “Introduction," op. cit., 10. 